\title{
Thermal and swirl flow topologies in a twisted square duct with a multi-twisted tape installed
}

\author{
Pitak PROMTHAISONG ${ }^{*}$, Varesa CHUWATTANAKUL ${ }^{* *}$ and Smith EIAMSA-ARD* \\ "Department of Mechanical Engineering, Faculty of Engineering \\ Mahanakorn University of Technology, Bangkok, Thailand \\ "Faculty of Engineering, King Mongkut's Institute of Technology Ladkrabang, Bangkok, Thailand \\ E-mail: varesaatkmitl@gmail.com
}

Received: 10 October 2019; Revised: 29 January 2020; Accepted: 16 April 2020

\begin{abstract}
This paper presents 3D numerical investigation of the turbulent flow and heat transfer characteristics of a twisted square duct installed with multi-twisted tapes. Air was used as the working fluid with flow rates in terms of Reynolds numbers ranging from 3000 to 20,000. The effects of (1) multi-twisted tape width ratios $(w / H)$ of 0.2 to 1.0 and (2) the number of channels $(N=2$ and 4$)$ on heat transfer and flow mechanisms were studied at constant twist ratio of $y / D=3.5$. The numerical results showed that twisted square duct combined with twisted tape caused swirl flows which effectively promoted fluid mixing and provided heat transfer over those of both a straight smooth square duct and twisted square duct. Increasing $w / H$ led to increases in both heat transfer and the friction factor. At a given multi-twisted tape width ratio $(w / H)$, the heat transfer and friction factor with $N=4$ were higher than those with $N=2$, while thermal enhancement factor showed the opposite trend. A maximum thermal enhancement factor of 1.93 was obtained at tape width ratio of $w / H=1.0$, channel number of $N=2$ and $R e=$ 3000 .
\end{abstract}

Keywords : Heat transfer, Friction factor, Multi-twisted tapes, Thermal enhancement factor, Twisted square duct

\section{Nomenclature}

$A$

$A_{c}$

$D$

$D_{\mathrm{h}}$

$f$

$H$

$h$

$h_{\mathrm{x}}$

$k$

$k_{\text {air }}$

N

$N u$

$N u_{\mathrm{x}}$

$P$

$p$

$\operatorname{Pr}$

$P r_{\mathrm{t}}$

$\dot{q}_{\text {conv. }}$

$\dot{q}_{\text {input }}$ heat transfer area, $/ \mathrm{m}^{2}$ cross section area, $/ \mathrm{m}^{2}$

characteristic diameter of a twisted duct, $/ \mathrm{m}$

hydraulic diameter, /m

friction factor

cross-sectional length, $\mathrm{m}$

convective heat transfer coefficient, $/ \mathrm{W} \mathrm{m}{ }^{-2} \mathrm{~K}^{-1}$

local convective heat transfer coefficient, $/ \mathrm{W} \mathrm{m}^{-2} \mathrm{~K}^{-1}$

turbulent kinetic energy

thermal conductivity of air, $/ \mathrm{W} \mathrm{m}^{-1} \mathrm{~K}^{-1}$

number of channel flows

average Nusselt number

local Nusselt number

wetted perimeter of the cross-section, $/ \mathrm{m}$

static pressure, $/ \mathrm{Pa}$

Prandtl number

turbulent Prandtl number

convection heat transfer, $\mathrm{W} \mathrm{m}^{-2}$

heat flux input, $\mathrm{W} \mathrm{m}^{-2}$ 


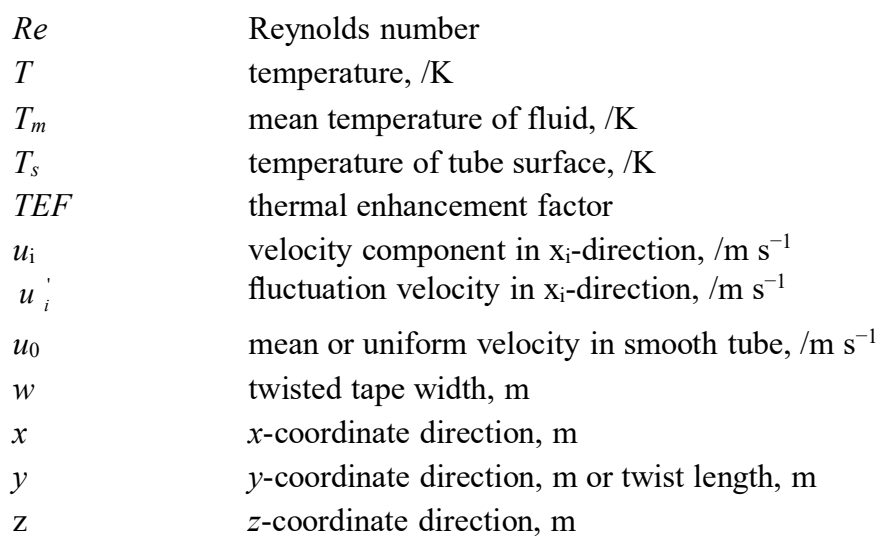

$\begin{array}{ll}\text { Greek letters } & \\ \mu & \text { dynamic viscosity, } / \mathrm{kg} \mathrm{s}^{-1} \mathrm{~m}^{-1} \\ \Gamma & \text { thermal diffusivity } \\ \varepsilon & \begin{array}{l}\text { dissipation rate } \\ \text { density, } / \mathrm{kg} \mathrm{m}^{-3}\end{array} \\ \rho & \\ \text { Subscripts } & \\ 0 & \text { straight smooth square duct } \\ \mathrm{pp} & \text { pumping power } \\ \mathrm{t} & \text { turbulent } \\ \text { conv } & \text { convection }\end{array}$

\section{Introduction}

Several heat transfer enhancement techniques have been devised for more compact heat exchangers. Increasing fluid mixing using turbulators is one important approach. The main purpose of a turbulator is to generate vortex/swirl flow leading to increased convective heat transfer or heat transfer enhancement (Eiamsa-ard et al., 2013; Saysroy and Eiamsaard 2017). Twisted tapes, one type of turbulator, are extensively applied to increase heat transfer in a tube heat exchanger. A swirl flow induced by twisted tapes effectively disrupts thermal boundary layers, and thus facilitating heat transfer. Chokphoemphun et al. (2015) reported the thermal performance of a tubular heat exchanger with multiple twisted-tape inserts in a turbulent flow regime. The multiple twisted-tape inserts were fixed at a twist ratio of $y / w=4$. They found that heat transfer increases incrementally with both the Reynold number and the number of twisted-tapes. The heat transfer and friction factor were found to increase by 2.12 and 4.1 times, respectively, over those of a plain tube. A quadruple counter-twisted tape provided the maximum thermal performance. Piriyarungrod et al. (2018) presented the thermohydraulic performance of a heat exchanger tube into which multiple twisted-tapes were inserted. The effects of the twist ratio and the number of the small twisted tapes $(y / w=2.5,5,10,15,20$ and 25 and $N=2,3,4,5$ and 6$)$ were examined. They found that increasing the number of tapes $(N)$ led to increased heat transfer and friction factors over that of a single twisted tape. The maximum thermo-hydraulic performance factor 1.2 was found with the use of multi-twisted tapes, $N=6$ and a twist ratio of $y / w=2.5$. Eiamsa-ard et al. (2010) investigated the effect of dual twisted tapes on counter/co-swirling flows and heat transfer enhancement in a round tube. Dual counter twisted tapes (CTs) were used as counter-swirl flow generators, while dual co-twisted tapes (CoTs) were used as co-swirl flow generators in a test section. CTs and CoTs with four different twist ratios $(y / w=2.5,3.0,3.5$ and 4.0) were applied at Reynolds numbers ranging between 3700 and 21,000. They found that the Nusselt number, friction factor and thermal enhancement index increased with decreasing twist ratio $(y / w)$. The heat transfer rates in the tube fitted with CTs were increased up to $44.5 \%$ and $50 \%$ higher than those with CoTs and single twisted tape, respectively. The maximum thermal enhancement factor was found at 1.39 using CTs with a twist ratio of $y / w=2.5$. Hong et al. (2018) studied the effect of short length helical tapes on heat transfer enhancement. Tape length ratios $(L / D)$ of 31-46.6, hole diameter ratios $(W / D)$ of $0.28-0.41$ and pitch length ratios $(P / D)$ of 1.03-1.7 were studied. They found that heat transfer and friction factor were higher than those of the plain tube by 
around 2.6 times and 16.3 times, respectively. Promvonge (2015) applied twisted tapes combined with a V-finned turbulator in a square-duct heat exchanger. The effect of the pertinent $V$-fin parameters, such as the four relative fin height ratios, $e / w=0.16-0.42$ and relative fin pitch of $P / w=4-16$ at a single fin attack angle of $\alpha=30^{\circ}$ on thermal characteristics were investigated. The highest thermal performance of 1.75 was achieved by using the V-finned turbulator with $e / w=0.21$ and $P / w=4.0$. Eiamsa-ard and Changcharoen (2015) presented the flow structure and heat transfer performance in a square duct fitted with dual/quadruple twisted-tapes using various configurations in a turbulent region. They found that the highest thermal performance factors for the Co-DTs, Co-DDTs, C-DTs, C-DDTs, Co-QTs, PC-QTs and CC-QTs, were around 1.21, 1.35, 1.25, 1.38, 1.08, 1.18, and 1.22, respectively. Yadav et al. (2015) used square and hexagonal ducts with twisted tape inserts in laminar flow regime. Their results showed that Nusselt number and friction factor increased as the side of non-circular duct increased. The highest Nusselt number and friction factor were found by using the tube with twisted tapes.

Additionally, twisted tube/ducts were used for heat transfer enhancement. Swirl flow was generated by a twisted tube/duct in a similar fashion as the twisted taped. Bhadouriya et al. (2015) reported the effect of fluid flow and heat transfer in a twisted square duct with twist ratios between 2.5 and 20. They found that the maximum Nusselt number and friction factor were found at a twist ratio of 2.5. Castelain et al. (2001) studied of chaotic advection regime in a twisted duct flow. Khoshvaght-Aliabadi et al. (2018) investigated the heat transfer enhancement in heat exchange devices with spirally-coiled twisted-ducts using $\mathrm{Cu}$ /water nanofluids with concentrations of $0.5 \%$ and $1 \%$ by mass as the working fluids. A spirally-coiled twisted-duct with twist-pitches, $t_{p}$, of $0.05-0.15 \mathrm{~m}$ and coil-pitches, $c_{p}$, of $0.015-0.035 \mathrm{~m}$ were employed. The maximum augmentation of the Nusselt number and friction factor were found by using the spirally-coiled twisted-ducts with $t_{p}=0.05 \mathrm{~m}$ and $c_{p}=0.015 \mathrm{~m}$. Kongkaitpaiboon et al. (2019) used corrugated tubes with various numbers of starts and depth ratios heat transfer enhancement. It was found that a corrugated tube generated swirl flow which improved fluid mixing and augmented heat transfer rate. The resultant Nusselt numbers and thermal performance factors were respectively increased up to 2.16 and 1.2 times of those of the straight circular tube. Promthaisong et al. (2018) employed helical oval tubes with different depth ratios and pitch ratios for heat transfer enhancement. The maximum thermal performance of 1.3 was obtained by using a helical oval tube with a depth ratio of 0.05 and a pitch ratio of 0.6 at a low Reynolds number of 5000. Moreover, the use of twisted tube together with twisted tape resulted in further heat transfer enhancement as compared to that of the twisted tube alone. Wongcharee and Eiamsa-ard (2012) utilized corrugated tubes equipped with twisted tapes. Promthaisong et al. (2017) employed corrugated tubes with a fivechannel twisted tape inserts. Eiamsa-ard et al. (2016) reported the effect of a three-start spirally twisted tube inserted with triple-channel twisted tapes on heat transfer enhancement. The compound devices showed a drastic increase in heat transfer, yielding a maximal thermal performance as high as 1.3 .

The twisted tubes with the twisted tapes in different designs and geometries were proposed such as twisted tube in form of three-start spirally twisted tube (Eiamsa-ard et al., (2016), Samruaisin et al., (2019)) and oval tube (KhoshvaghtAliabadi and Feizabadi, (2020)). The present work focuses on the twisted square duct, which show different heat transfer phenomenon from twisted tubes reported in the previous studies since a square duct possesses four corners which make heat transfer is more difficult. The present work proposes the use of multi-twisted tapes in twisted square ducts aiming to further promote turbulent fluid mixing and heat transfer. Moreover, the effects of multi-twisted tape width ratios and numbers of channels for flow are investigated since swirl flow characteristics are strongly dependent on the parameters of a multi-twisted tape. 3D numerical simulation was performed to gain a deep understanding of flow and heat transfer phenomena. The flow structure, temperature field and local wall Nusselt number distribution are reported.

\section{Physical model of a twisted square duct with an installed multi-twisted tape}

The systems of interest are twisted square ducts with multi-twisted tapes installed, as depicted in Fig. 1. The twist ratio $(y / D)$ of twisted square duct and multi-twisted tape are set to 3.5 , where $D$ is the characteristic diameter $(D=0.05$ $\mathrm{m})$ of the duct. The duct and tape with twist ratio $(y / D)$ of 3.5 were chosen due to their promising thermal enhancement factor $(T E F)$. The parameters $w$ and $H$ are the multi-twisted tape width and cross-section length, respectively, and the parameter $N$ is the number of flow channels. In general, a typical twisted tape has $N=2$ (Castelain et al., 2001, Eiamsaard and Changcharoen, 2015, Hong et al., 2018). However, heat transfer rate and the pressure loss increase with increasing the number of flow channels $(N)$. In order to keep pressure loss low, the tapes with and $N=2$ and 4 were selected in the present work. The simulation encompassed $(1)$ two $(N=2)$ and four channel $(N=4)$ multi-twisted tapes with width ratios 
$(w / H)$ ranging from 0.2 to 1.0 , and (2) Reynolds numbers ranging from 3000 to 20,000 . The grid used in the computational domain consisted of hexahedron elements. For the viscous sublayer near the walls, where the momentum and temperature significantly change, the hexahedron grids were applied with higher density than those in other regions. The high-density grids at the near-wall regions were set to $y^{+} \approx 1$.

\section{Boundary condition}

The inlet and outlet of the flow domain were applied with periodic boundaries. 1. For the periodic boundary of the fluid flow, a mass flow rate is applied as the initial condition for the iteration by using periodic technique. The outlet condition was used for repeating calculation until the velocity profiles at the outlet and inlet are similar. For the periodic boundary of the heat transfer, an inlet fluid temperature of $300 \mathrm{~K}$ is applied as the initial condition for the iteration by using periodic technique under constant wall heat flux. The outlet condition was used for repeating calculation until the difference between of inlet and outlet temperature becomes constant. The physical properties of the air have been assumed to remain constant at average bulk temperature. Impermeable boundary and no-slip wall conditions have been implemented over the twisted square duct walls as well as the multi-twisted tape. The tape was treated as an insulator. A heat flux at the twisted square duct wall was maintained constant at $600 \mathrm{~W} / \mathrm{m}^{2}$.

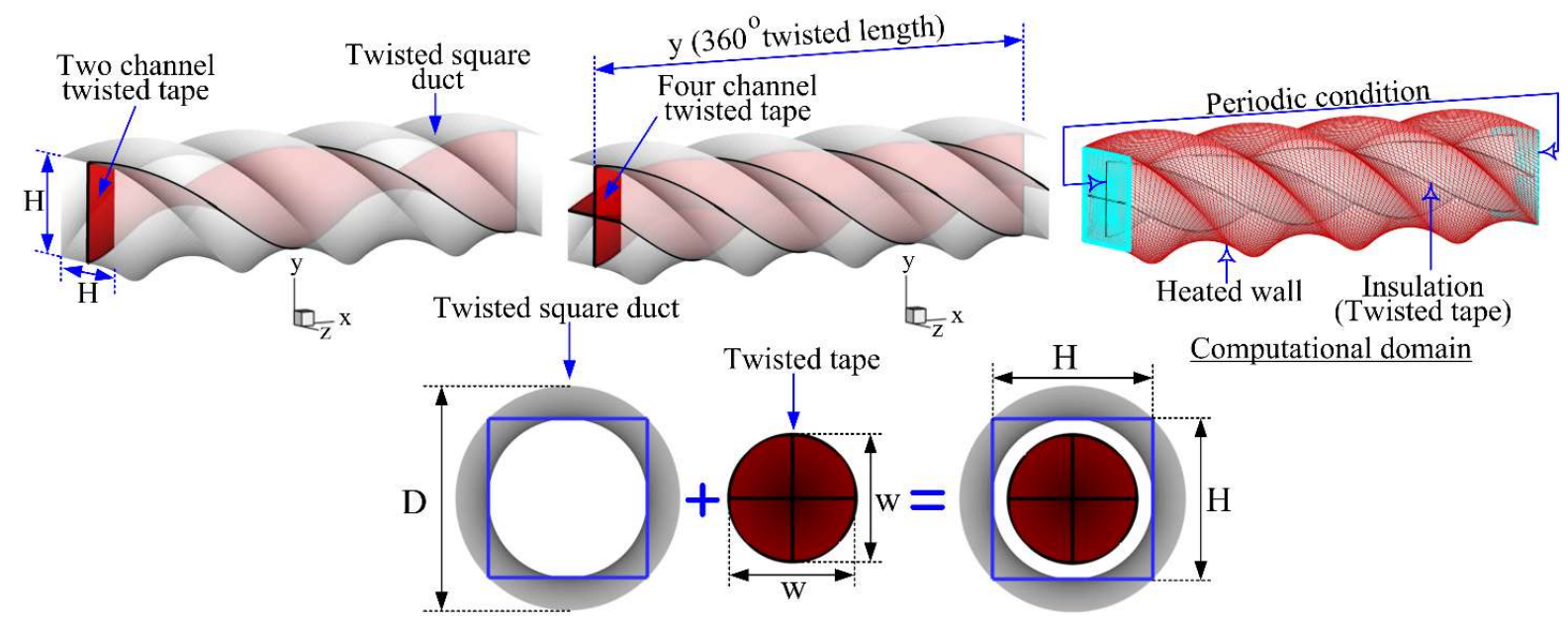

Fig. 1 Geometry of a twisted square duct fitted with multi-twisted tapes

\section{Data reduction}

The assumptions of the numerical model for fluid flow and heat transfer in a twisted square duct with inserted multitwisted tapes are:

- Flow that is steady, incompressible and turbulent

- Three-dimensional fluid flow and heat transfer

- The fluid properties are constant

- Negligible radiation heat transfer

Based on the above assumptions, the tube flow is governed by the continuity, Navier-Stokes and energy equations. In the Cartesian tensor system, these equations can be written as follows:

Continuity equation:

$$
\frac{\partial}{\partial x_{i}}\left(u_{i}\right)=0
$$

Momentum equation:

$$
\frac{\partial}{\partial x_{j}}\left(\rho u_{i} u_{i}\right)=-\frac{\partial p}{\partial x_{i}}+\frac{\partial}{\partial x_{j}}\left[\mu\left(\frac{\partial u_{i}}{\partial x_{j}}+\frac{\partial u_{j}}{\partial x_{i}}\right)-\rho \overline{u_{i}^{\prime} u_{j}^{\prime}}\right]
$$

where $\rho$ is the fluid density fluid, and $u_{i}$ is a mean component of velocity in the $x_{i}$ direction, $p$ is the pressure, $\mu$ is the dynamic viscosity, and $u^{\prime}$ is a fluctuating component of velocity. Repeated indices indicate summation from one to three for $3 \mathrm{D}$ problems. 
Energy equation:

$$
\frac{\partial}{\partial x_{j}}\left(\rho u_{i} T\right)=\frac{\partial}{\partial x_{j}}\left(\left(\Gamma+\Gamma_{t}\right) \frac{\partial T}{\partial x_{j}}\right)
$$

where $\Gamma$ and $\Gamma_{\mathrm{t}}$ are molecular and turbulent thermal diffusivity, respectively, and are given by:

$$
\Gamma=\frac{\mu}{\operatorname{Pr}}, \text { and } \Gamma_{t}=\frac{\mu_{t}}{\operatorname{Pr}_{t}}
$$

The Reynolds-averaged approach to turbulent modeling requires that the Reynolds stresses, $-\rho \overline{u_{i}^{\prime} u_{j}^{\prime}}$ in Eq. (2) be modeled. The Boussinesq hypothesis relates the Reynolds stresses to the mean velocity gradients as seen in the following equation:

$$
-\rho \overline{u_{i}^{\prime} u_{j}^{\prime}}=\mu_{t}\left(\frac{\partial u_{i}}{\partial u_{j}}+\frac{\partial u_{j}}{\partial u_{i}}\right)-\frac{2}{3}\left(\rho k+\mu_{t} \frac{\partial u_{i}}{\partial x_{i}}\right) \delta_{i j}
$$

where $k$ is the turbulent kinetic energy, defined by $k=\frac{1}{2} \overline{u_{i}^{\prime} u_{i}^{\prime}}$ and $\delta_{i j}$ is a Kronecker delta. An advantage of the Boussinesq approach is the relatively low computational costs associated with computation of the turbulent viscosity, where $\mu_{t}$ is given as $\mu_{\mathrm{t}}=\rho \mathrm{C}_{\mu} k^{2} / \varepsilon$. The realizable $k$ - $\varepsilon$ turbulence model was used for all computational domains in the turbulent region. The details of the governing equations and the realizable $k-\varepsilon$ turbulent model have been presented by Promthaisong and Suwannapan (2018). There are four parameters of interest in the present work, namely, the Reynolds number, friction factor, Nusselt number and thermal performance enhancement factor.

The Reynolds number is defined as:

$$
\operatorname{Re}=\frac{\rho u_{0} D_{h}}{\mu}
$$

where $D_{h}$ is the hydraulic diameter which can be calculated from $4 A_{c} / P$, where $A_{c}$ is the cross-section area and $\mathrm{P}$ is the wetted perimeter of the cross-section.

The friction factor can be calculated from:

$$
f=\frac{(-d p / d x) D_{h}}{(1 / 2) \rho \bar{u}^{2}}
$$

The Newton's law of cooling (Incropera et al., 2006) can be expressed as:

$$
\dot{q}_{\text {conv }}=h\left(T_{s}-T_{m}\right)
$$

For no-slip condition at the tube surface, the heat transfer from the tube surface to the first layer of the fluid next to the surface takes place solely via conduction under constant heat flux condition. The heat transfer equation can be expressed as:

$$
\dot{q}_{\text {conv }}=\dot{q}_{\text {input }}
$$

where the heat flux $\left(\dot{q}_{\text {input }}\right)$ is kept constant at $600 \mathrm{~W} / \mathrm{m}^{2}$

$$
\begin{aligned}
& h=\frac{\dot{q}_{\text {input }}}{\left(T_{s}-T_{m}\right)} \\
& N u_{x}=\frac{h_{x} D_{h}}{k_{\text {air }}}
\end{aligned}
$$

where $h$ and $k_{\text {air }}$ are the convective heat transfer coefficient and thermal conductivity of air, respectively.

The area-average Nusselt number can be obtained from:

$$
N u=\frac{1}{A} \int N u_{x} \partial A
$$

A measure of performance accounting for both heat transfer and pressure loss for equal pumping power, the thermal enhancement factor (TEF) suggested by Promvonge and Skullong (2020) can be expressed as

$$
T E F=\left(\frac{N u}{N u_{0}}\right)_{R e} /\left(\frac{f}{f_{0}}\right)_{\mathrm{Re}}^{\frac{16}{55}}
$$

where $N u_{0}$ and $f_{0}$ are the Nusselt number and friction factor for a straight smooth square duct, respectively. 


\section{Results and discussion 5.1 Validation}

The computational domain was resolved with hexahedron elements and five grid densities of 50,000, 150,000, $350,000,500,000$ and 700,000 nodes were used to investigate the grid independence of the solution. The numerical results showed that variation in the Nusselt number $(\mathrm{Nu})$ and friction factor $(f)$ changes were marginal $(<0.2 \%)$ when the number of nodes increased from 500,000 to 700,000. Hence, a grid with 500,000 nodes was adopted for the current computations. The present numerical data (Nusselt numbers and friction factors) of the straight smooth square duct were compared with those by Incropera et al. (2006) and Promvonge et al. (2014) under a similar operating condition, as shown in Fig. 2(a). The present numerical results are in excellent agreement with those reported in both references (deviations less than 5\%). The fluid flow and heat transfer results for the straight smooth square duct with twisted tape inserted $(N=2, w / H=1.0$ and $y / w=4.0$ ) by using the Realizable $k$ - $\varepsilon$ turbulence model were compared with the experimental data by Promvonge $e t$ al. (2014) as presented in Fig. 2(b). Under similar conditions, the numerical result provided the similar trend with the experimental data for both the Nusselt number and friction factor and gave the mean deviations less than $10 \%$ for both the Nusselt number and friction factor. Therefore, the Realizable $k$ - $\varepsilon$ turbulence model can be applied for the duct inserted with twisted tape in which swirl flow was generated.

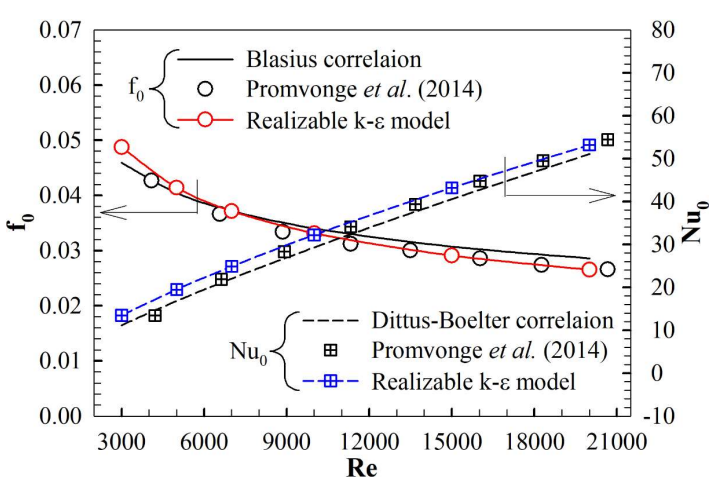

(a)

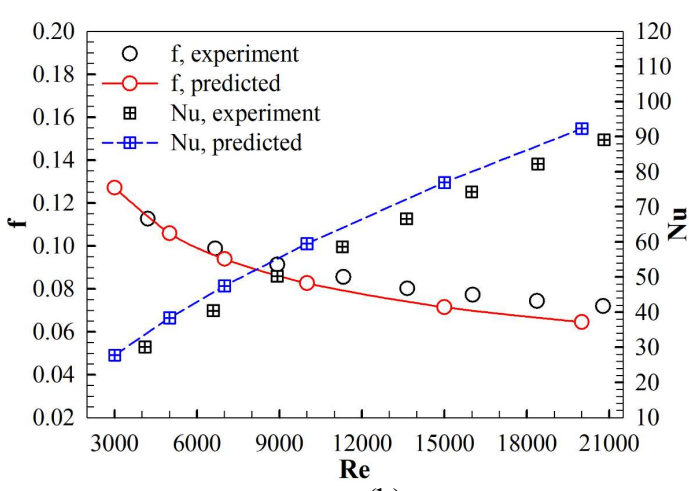

(b)

Fig. 2 Verification of (a) $N u_{0}$ and $f_{0}$ for a straight smooth square duct and (b) straight smooth square duct inserted with twisted tape.

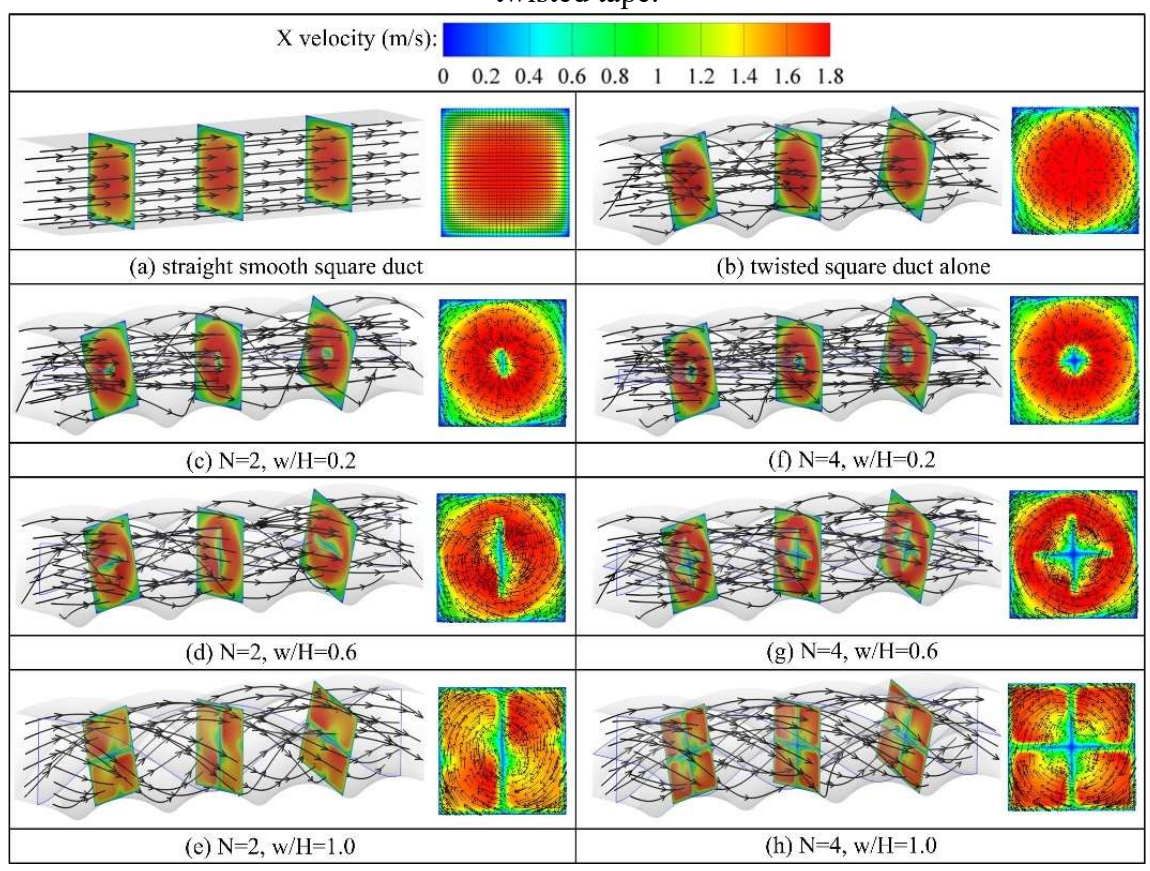

Fig. 3 3D flow structure, velocity vector and $x$-velocity distribution in the transverse plane for $R e=3000$ 


\subsection{Flow topology}

Figure 3 displays the 3D flow topology, velocity vector and $\mathrm{x}$-velocity distribution in the transverse plane for $R e=$ 3000. In a straight smooth square duct, only axial flow was detected. In twisted square ducts, swirl flows were generated near-wall region while axial flow appeared around the core region. The flow structures in the twisted square ducts (for both $N=2$ and $N=4$ channels) with the tape having the smallest width ratio of ( $w / H=0.2)$ were similar to that in twisted square ducts without tape. The results indicate that the narrow multi-twisted tape has insignificant effect on the flow structure. As the tape width ratio $(w / H)$ was increased, the effect of swirl flow induced by the multi-twisted tape became significant. The use of the tapes at $w / H=1.0$ (tight-fit multi-twisted tapes) resulted in fully swirling flow in the ducts with both $N=2$ and $\mathrm{N}=4$ channels confirmed by the flow vectors in the transverse plane which showed that $x$-velocity distributed over the whole cross-sectional area. The flow helped in promoting fluid mixing between the core and duct wall region.

\subsection{Heat transfer and friction loss}

Figure 4 presents the fluid temperature field in 3D (iso-surface) and 2D (on the transverse plane) forms at $R e=3000$. Evidently, there was a considerable difference between core and wall temperatures, indicating high heat transfer resistance in the straight smooth square duct due to the laminar axial flow. For the twisted square duct alone and the ones with loosefit multi-twisted tape cases $(w / H=0.2-0.8)$, the temperature distributions were affected by swirl flows. However, the difference between core and wall temperatures were still significant since the tapes with small widths induced low swirling intensity resulting in poor fluid mixing between the core and near the duct wall for both tubes with $N=2$ and $N$ $=4$ channels. On the other hand, the temperature distribution in the duct equipped with the tapes having width ratio $(w / H)$ of 1.0 was fairly uniform, especially the one with $N=4$ channels. The results revealed that the tape width and the channel number of ducts are important parameters affecting fluid mixing. However, the effect of tape width is more dominant than that of the channel number of ducts. The local temperature distributions presented in Figure 5 are accorded with the results in Fig. 4. The straight smooth square duct and the one with the tapes having small widths showed high duct wall temperatures, especially around the corners where dead zones existed. As the tape width ratio $(w / H)$ was increased, the sizes of the dead zones were reduced owing to the stronger swirling flow.

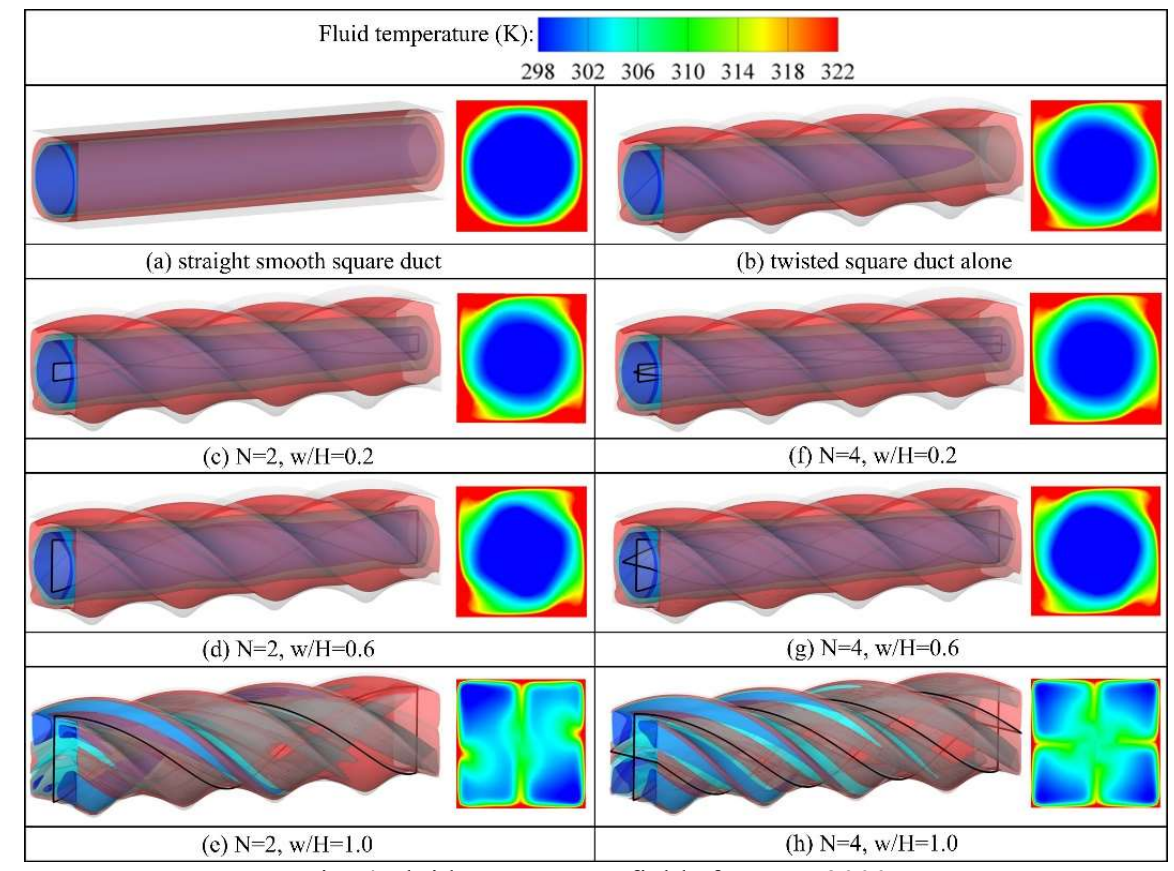

Fig. 4 Fluid temperature fields for $\operatorname{Re}=3000$

The local wall Nusselt number distributions for a Reynolds number (Re) of 3000 are displayed in Fig. 6. Obviously, the twisted square duct yielded larger areas with high Nusselt numbers as compared to the straight smooth square duct due to the effect of the swirling flow. For the ducts with twisted tape, Nusselt numbers increased with increasing the tape width ratio $(w / H)$. The ducts with $N=4$ channels and the tape having $w / H=1.0$ yielded the highest Nusselt number due 
to the excellent fluid mixing as mentioned above. It should be noted that the duct with the tapes having $w / H=0.2$ and 0.6 (loose-fit multi-twisted tapes) yielded low Nusselt number for both $N=2$ and $N=4$. In addition, this was similar to a twisted square duct alone since the fluid flow was only disrupted at the core by the tape. However, the same $w / H, N=4$ channels gave a higher Nusselt number than for $N=2$, as is shown in Fig. 7. A combination of methods gave a higher Nusselt number than the twisted square duct alone.

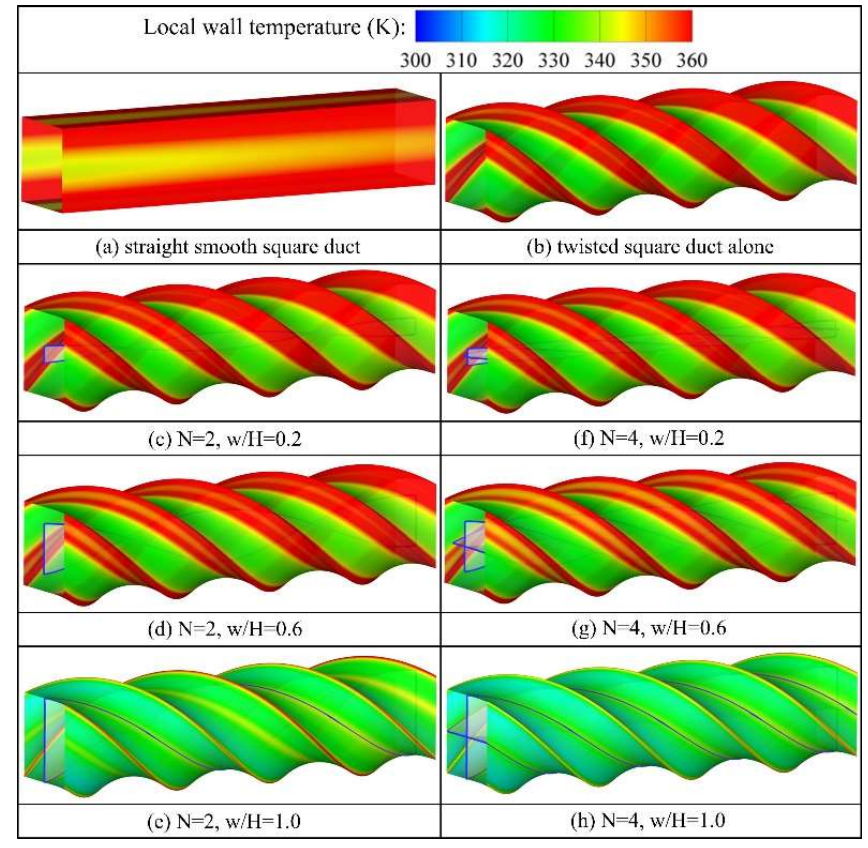

Fig. 5 Local wall temperature distributions for $R e=3000$

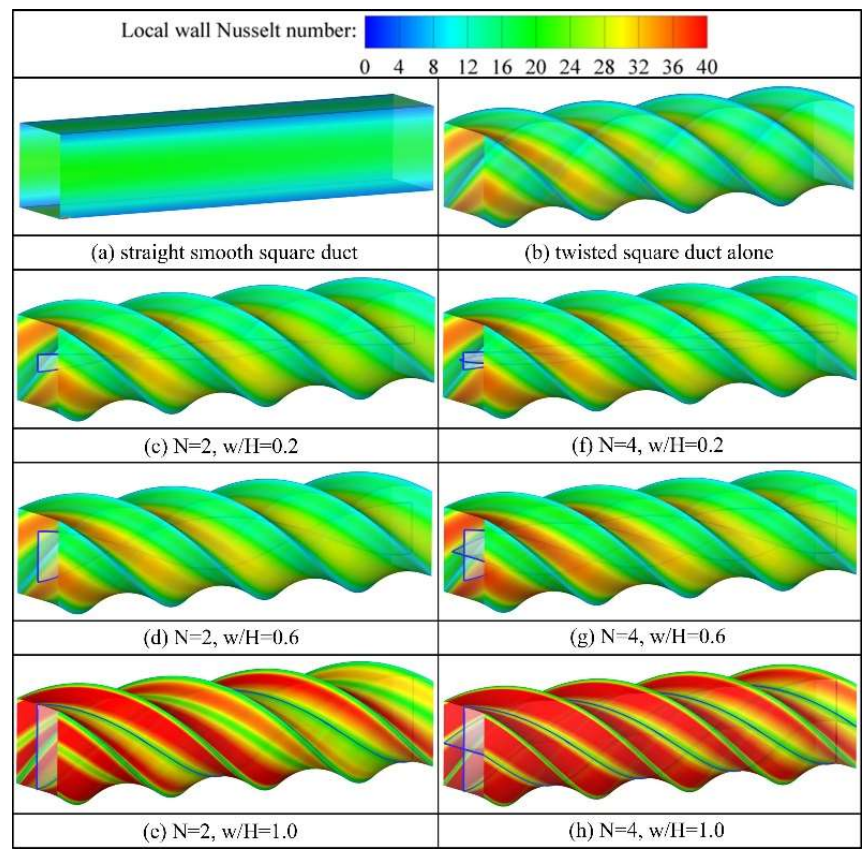

Fig. 6 Local wall Nusselt number distributions for $R e=3000$

Figure 8 presents the variation of the Nusselt number ratio $\left(N u / N u_{0}\right)$ with Reynolds number $(R e)$. Nusselt number ratio $\left(\mathrm{Nu} / \mathrm{Nu} u_{0}\right)$ decreased with increasing $R e$ in all cases. At a given $R e$, the twisted square duct alone and twisted square ducts with multi-twisted tapes yielded higher heat transfer rates than the straight smooth square duct $\left(N u / N u_{0}>1.0\right)$ owing to the generation of swirling flow that helped to promote fluid mixing. In the similar manner, the twisted square ducts with multi-twisted tape yielded higher heat transfer rate than the twisted square duct alone. Furthermore, the ducts with $N=4$ 
Promthaisong, Chuwattanakul and Eiamsa-ard, Journal of Thermal Science and Technology, Vol.15, No.1 (2020)

channels showed better performance in heat transfer enhancement than the ones with $N=2$ channels. As the tape width ratio $(w / H)$ increased, heat transfer increased. Over the studied Re range, the twisted square duct alone gave $N u / N u_{0}$ ranging from 1.28 to 1.76 . The ducts with $N=2$ and $N=4$ gave $N u / N u_{0}$ ranging from 1.29 to 3.09 and 1.31 to 3.33 , respectively which were higher than those of the twisted square duct alone by $0.53-75.47 \%$ and $1.98-88.87 \%$, respectively. The twisted ducts with $N=4$ gave higher $N u / N u_{0}$ than the ones with $N=2$ by around $1.44-7.63 \%$. The ducts $N=4$ and containing the tapes having $w / H=1.0$ yielded the highest $N u / N u_{0}$ of 3.33 at $R e=3000$.

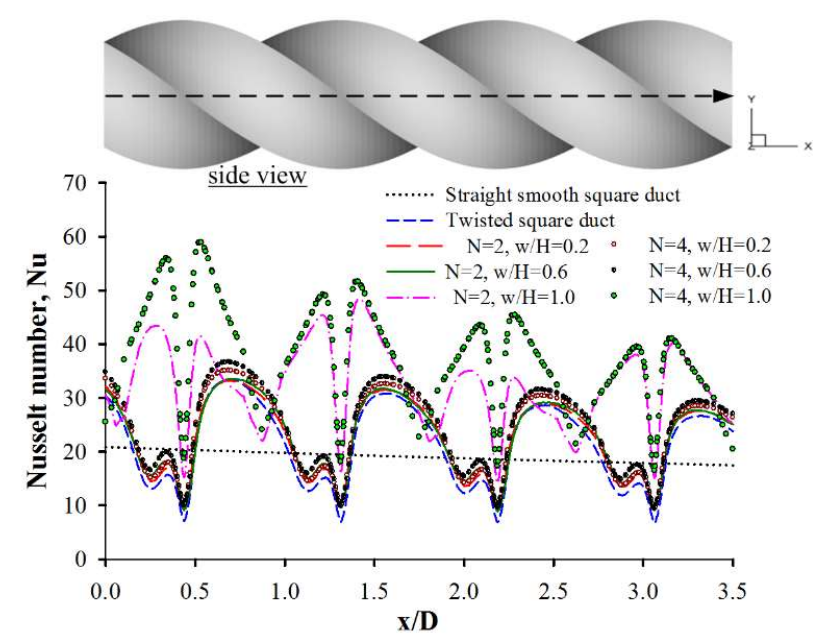

Fig. 7 Local wall Nusselt number profiles for $R e=3000$

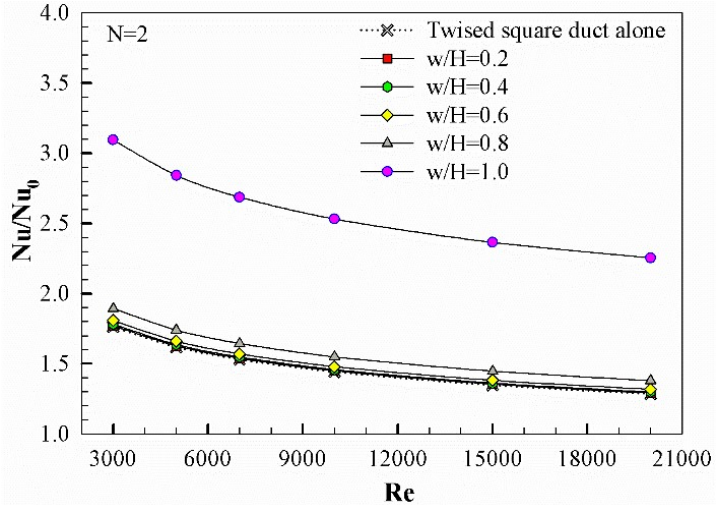

(a) $N=2$

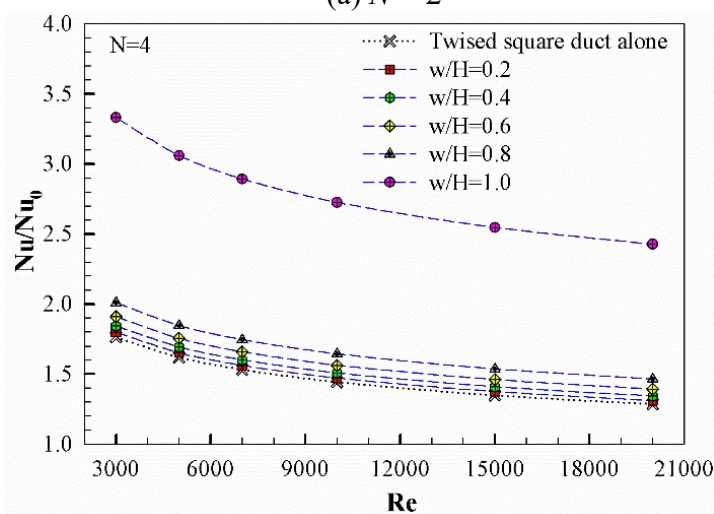

(c) $N=4$

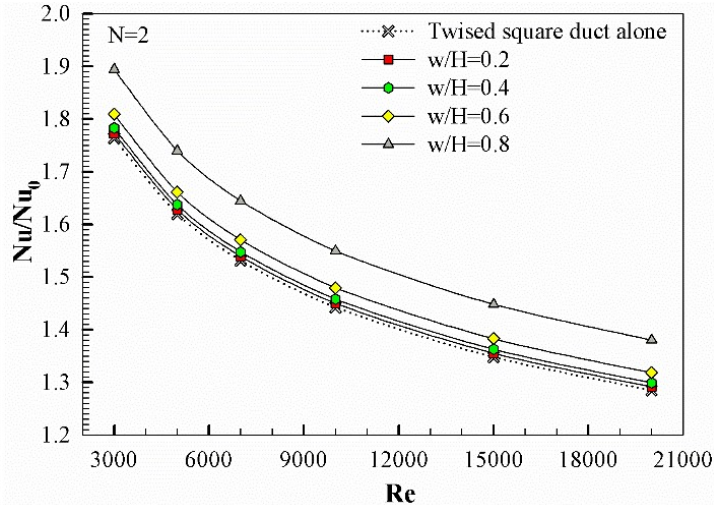

(b) $N=2$ (zoom scale)

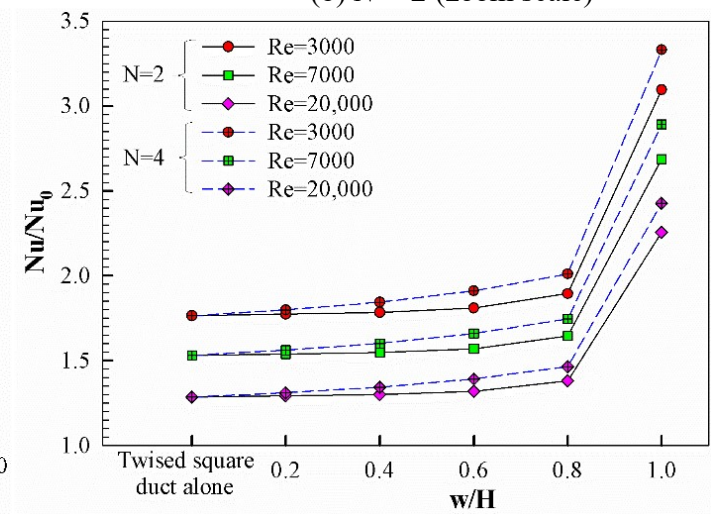

(d) comparison between $N=2$ and $N=4$

Fig. 8 Influences of multi-twisted tape width ratios $(w / H)$ and number of tape channels $(N)$ on the Nusselt number ratio $\left(\mathrm{Nu} / \mathrm{Nu} u_{0}\right)$ 
The variation of friction factor ratio $\left(f / f_{0}\right)$ with Reynolds number $(R e)$ is presented in Fig. 9. Friction factor ratio $\left(f / f_{0}\right)$ tended to decrease with increasing $R e$ in all cases. The use of the twisted square duct alone and the twisted square ducts combined with multi-twisted tapes resulted in higher than that found by the use of the straight smooth square duct $\left(f / f_{0}>\right.$ 1.0) because of flow blockage by the duct rough surface and twisted tapes. The twisted square ducts equipped with multitwisted tapes caused higher $f / f_{0}$ than the twisted square duct alone. The increase of $N$ resulted in higher friction loss penalty. Over the Re range studied, the use of the twisted square duct alone showed $f / f_{0}$ ranging from 1.56 to 1.92 . The ducts with $N=2$ and $N=4$ caused $f / f_{0}$ ranging from 1.87 to 4.98 and 2.03to 6.48, respectively which were higher than those of the twisted square duct alone by $19.8-159 \%$ and $29.95-237 \%$, respectively. The twisted ducts with $N=4$ caused higher $f / f_{0}$ than the ones with $N=2$ by around $8.48-32.27 \%$. The ducts $N=4$ and containing the tapes having $w / H=1.0$ caused the highest $f / f_{0}$ of 6.48 at $R e=3000$.

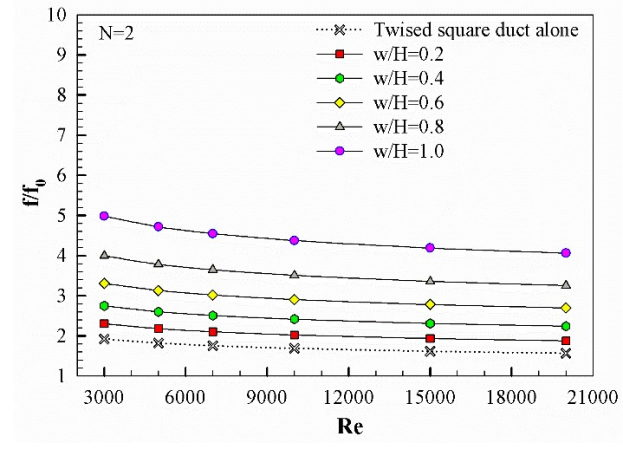

(a) $N=2$

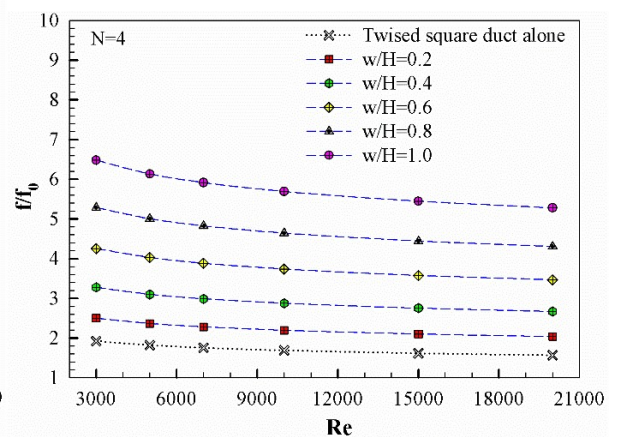

(b) $N=4$

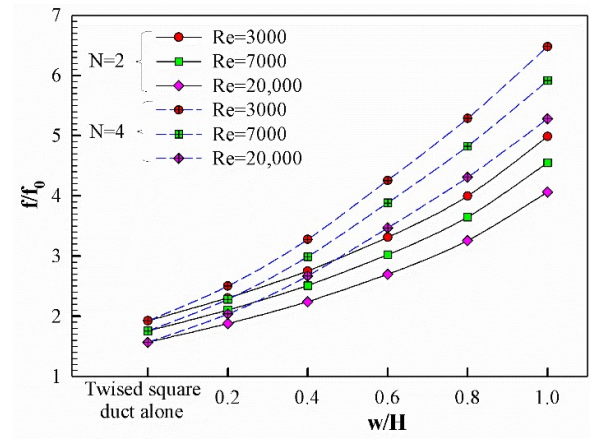

(c) effect of channel number $(N)$

Fig. 9 Influences of multi-twisted tape width ratio $(w / H)$ and channel number $(N)$ on the friction factor

\subsection{Performance evaluation}

Figure 10 displays variation of the thermal enhancement factor $(T E F)$ with Reynolds number $(R e)$. Thermal enhancement factor $(T E F)$ tended to decrease with increasing $R e$ in all cases. In the range studied, the $T E F$ were in the range of 0.89-1.81 depending on the number of channels $(N)$, tape width ratio $(w / H)$ and $R e$. The ducts with the tapes having the tape width ratios of 0.2-0.8 gave a lower TEF than the twisted square duct alone due to the prominent effect of increased friction factor over that of enhanced heat transfer. On the other hand the ducts with $N=2$ and $N=4$ channels and tapes having for $w / H=1.0$ yielded higher $T E F$ than the twisted square duct alone because of the dramatic heat transfer enhancement. Although the ducts with $N=2$ channels yielded lower heat transfer than the one with $N=4$, they yielded higher $T E F$ the ones with $N=4$ due to their lower friction loss penalty. In the present study, the maximum $T E F$ of 1.93 was obtained by using the duct with $N=2$ containing the tapes having $w / H=1.0$ at $R e=3,000$. In addition, the results of the straight smooth square duct with multi-twisted tape by Ray and Date (2003), $N=2, w / H=1.0$ and $0.5, y / w=2.5$ are compared with those of the twisted square duct with multi-twisted tape, $N=2, w / H=1.0$ and $0.5, y / w=2.47(y / D=$ 3.5) which is the best case in the present work as presented in Fig. 10(a). The comparison revealed that the present case showed higher $T E F$ than the one by Ray and Date by around $60 \%$. This can be explained that the twisted square duct with multi-twisted tape caused better fluid mixing and thus higher the heat transfer than the straight smooth square duct with multi-twisted tape. 


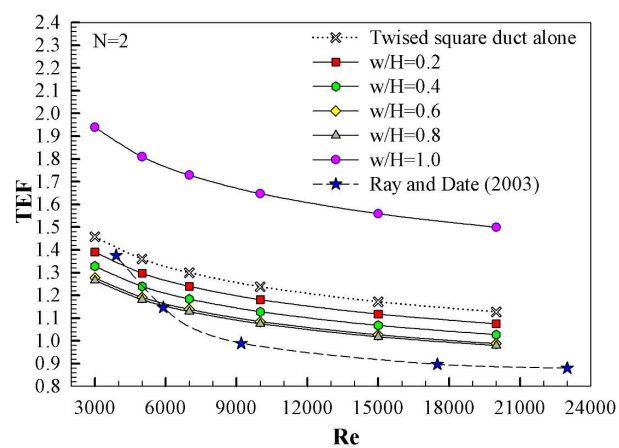

(a) $N=2$

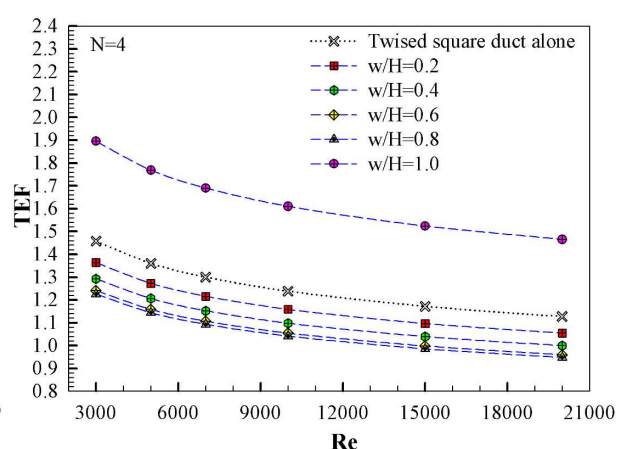

(b) $N=4$

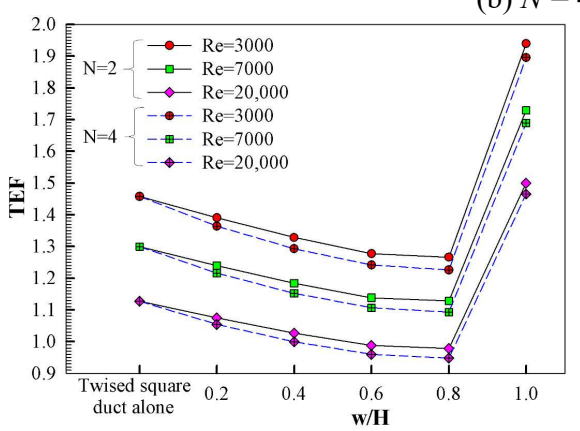

(c) comparison between $N=2$ and $N=4$

Fig. 10 Influences of multi-twisted tape width ratio $(w / H)$ and number of tape channels $(N)$ on the thermal enhancement factor

\section{Conclusions}

Twisted square ducts compounded with multi-twisted tapes created swirling flows that helped to increase heat transfer by improving fluid mixing between the core and near-wall regions. The use of twisted square ducts into with multi-twisted tapes resulted higher Nusselt number ratios $\left(N u / N u_{0}\right)$ and friction factor ratios $\left(f / f_{0}\right)$ than that of the twisted square duct alone. The Nusselt number ratio $\left(N u / N u_{0}\right)$ and friction factor ratio $\left(f / f_{0}\right)$ increased with increasing tape width ratio $(w / H)$. The ducts with $N=2$ and $N=4$ gave $N u / N u_{0}$ ranging from 1.29 to 3.09 and 1.31 to 3.33, respectively which were higher than those of the twisted square duct alone by $0.53-75.47 \%$ and $1.98-88.87 \%$, respectively. The ducts with $N=2$ and $N=4$ caused $f / f_{0}$ ranging from 1.87 to 4.98 and 2.03to 6.48 , respectively which were higher than those of the twisted square duct alone by $19.8-159 \%$ and $29.95-237 \%$, respectively. In the range studied, the $T E F$ were in the range of 0.89-1.81 depending on the number of channels $(N)$, tape width ratio $(w / H)$ and Reynolds number $(\operatorname{Re})$. The maximum $T E F$ of 1.93 was obtained by using the duct with $N=2$ containing the tapes having $w / H=1.0$ at $R e=3,000$.

\section{References}

Bhadouriya, R., Agrawal, A., and Prabhu S. V., Experimental and numerical study of fluid flow and heat transfer in a twisted square duct, International Journal of Heat and Mass Transfer, Vol. 82 (2015), pp. 143-158.

Castelain, C., Mokrani, A., Guer, Y. L., and Peerhossaini, H., Experimental study of chaotic advection regime in a twisted duct flow, European Journal of Mechanics - B/Fluids, Vol. 20 (2001), pp. 205-232.

Chokphoemphun, S., Pimsarn, M., Thianpong, C., and Promvonge, P., Thermal performance of tubular heat exchanger with multiple twisted-tape inserts, Chinese Journal of Chemical Engineering, Vol. 23 (2015), pp. 755-762.

Eiamsa-ard, S., and Changcharoen, W., Flow structure and heat transfer in a square duct fitted with dual/quadruple twisted-tapes: Influence of tape configuration, Journal of Mechanical Science and Technology, Vol. 29 (2015), pp. 3501-3518.

Eiamsa-ard, S., Kongkaitpaiboon, V., and Nanan, K., Thermohydraulics of turbulent flow through heat exchanger tubes fitted with circular-rings and twisted tapes, Chinese Journal of Chemical Engineering, Vol. 21 (2013) pp. 585-593. 
Eiamsa-ard, S., Promthaisong, P., Thianpong, C., Pimsarn, M., and Chuwattanakul, V., Influence of three-start spirally twisted tube combined with triple-channel twisted tape insert on heat transfer enhancement, Chemical Engineering and Processing: Process Intensification, Vol. 102 (2016), pp. 117-129.

Eiamsa-Ard, S., Thianpong, C., and Eiamsa-ard, P., Turbulent heat transfer enhancement by counter/co-swirling flow in a tube fitted with twin twisted tapes, Experimental Thermal and Fluid Science, Vol. 34 (2010), pp. 53-62.

Hong, Y., Du, J., Wang, S., Huang, S-M., and Ye, W-B., Effect of decaying swirl flow on tubular turbulent heat transfer enhancement by using short length helical tapes, Chemical Engineering Research and Design, Vol. 138 (2018), pp. $1-12$.

Incropera, F.P., and Dewitt, P.D., Introduction to Heat Transfer, $3^{\text {rd }}$ edition, 2006, John Wiley \& Sons Inc, New York.

Incropera, F.P., Dewitt, P.D., Bergman, T.L. and Lavine, A.S. Fundamentals of heat and mass transfer, 2006, John Wiley $\&$ Sons, New York.

Khoshvaght-Aliabadi, M., Feizabadi, A., Performance intensification of tubular heat exchangers using compound twistedtape and twisted-tube, Chemical Engineering and Processing - Process Intensification, Vol. 148 (2020), Article 107799.

Khoshvaght-Aliabadi, M., Khaligh, S. F., and Tavassoli, Z., An investigation of heat transfer in heat exchange devices with spirally-coiled twisted-ducts using nanofluid, Applied Thermal Engineering, Vol. 143 (2018), pp. 358-375.

Kongkaitpaiboon, V., Promthaisong, P., Chuwattanakul, V., Wongcharee, K., and Eiamsa-ard, S., Effects of spiral start number and depth ratio of corrugated tube on flow and heat transfer characteristics in turbulent flow region, Journal of Mechanical Science and Technology, Vol. 33 (2019), pp. 4005-4012.

Piriyarungrod, N., Manoj Kumar, Thianpong, C., Pimsarn, M., Chuwattanakul, V., and Eiamsa-ard, S., Intensification of thermo-hydraulic performance in heat exchanger tube inserted with multiple twisted-tapes, Applied Thermal Engineering, Vol. 136 (2018), pp. 516-530.

Promthaisong, P., and Suwannapan, S., Turbulent flow behaviors on thermal enhancement in a circular tube heat exchanger equipped with sinusoidal baffles, Journal of Research and Applications in Mechanical Engineering, Vol. 6 (2018), pp. 95-112.

Promthaisong, P., Jedsadaratanachai, W., and Eiamsa-ard, S., Numerical simulation and optimization of enhanced heat transfer in helical oval tubes: effect of helical oval tube modification, pitch ratio, and depth ratio, Heat Transfer Engineering, Vol. 39 (2018), pp. 1665-1685.

Promthaisong, P., Jedsadaratanachai, W., Chuwattanakul, V., and Eiamsa-ard, S., Simulation of turbulent heat transfer characteristics in a corrugated tube with five-channel twisted tape inserts, AIP Conference Proceedings, Vol. 1 (2017), pp. 020004.

Promvonge, P., and Skullong, S., Thermo-hydraulic performance in heat exchanger tube with V-shaped winglet vortex generator, Applied Thermal Engineering, Vol. 164 (2020), pp. 114424.

Promvonge, P., Suwannapan, S., Pimsarn, M., and Thianpong, C., Experimental study on heat transfer in square duct with combined twisted-tape and winglet vortex generators, International Communications in Heat and Mass Transfer, Vol. 59 (2014), pp. 158-165.

Promvonge, P., Thermal performance in square-duct heat exchanger with quadruple V-finned twisted tapes, Applied Thermal Engineering, Vol. 91 (2015), pp. 298-307.

Ray, S., and Date, A.W., Friction and heat transfer characteristics of flow through square duct with twisted tape insert, International Journal of Heat and Mass Transfer, Vol. 46 (2003), pp. 889-902.

Samruaisin, P., Kunlabud, S., Kunnarak, K., Chuwattanakul, V., Eiamsa-ard, S., Intensification of convective heat transfer and heat exchanger performance by the combined influence of a twisted tube and twisted tape, Case Studies in Thermal Engineering, Vol. 14 (2019), Article 100489.

Saysroy, A., Eiamsa-ard, S., Periodically fully-developed heat and fluid flow behaviors in a turbulent tube flow with square-cut twisted tape inserts, Applied Thermal Engineering, Vol. 112 (2017) pp. 895-910.

Wongcharee, K., and Eiamsa-ard, S., Heat transfer enhancement by using $\mathrm{CuO} /$ water nanofluid in corrugated tube equipped with twisted tape, International Communications in Heat and Mass Transfer, Vol. 39 (2012), pp. 251257.

Yadav, R. J., Kore, S., Raibhole, V. N., and Joshi, P. S., Development of correlations for friction factor and heat transfer coefficient for square and hex duct with twisted tape insert in laminar flow, Procedia Engineering, Vol. 127 (2015), pp. 250-257. 